\title{
Yaşlılarda Epilepsi
} Epilepsy in the Elderly

\author{
Belgin Petek Balc1 ${ }^{1}$, Aytül Mutlu1 ${ }^{1}$, Feriha Özer ${ }^{2}$, Özlem Çokar ${ }^{1}$ \\ ${ }^{1}$ Haseki Eğitim ve Araştırma Hastanesi, Nöroloji Kliniği, İstanbul, Türkiye \\ 2Medipol Üniversitesi Tıp Fakültesi, Nöroloji Anabilim Dalı, İstanbul, Türkiye
}

\section{Özet}

Amaç: Epilepsi yaşlılarda sık görülen bir hastalıktır, ancak etiyolojisi, klinik sunumu, eşlik eden hastalıkları ve prognozu genç hastalardan farklıdır. Bu çalışmada epilepsi nedenleri, yaşlılarda nöbet tipleri, elektroensefalografi (EEG) bulguları araştırıldı.

Gereç ve Yöntem: İlk epileptik nöbetini geçiren ve altmış beş yaş üzerinde 95 hasta retrospektif olarak değerlendirildi. Yaş, epilepsi tipi, EEG bulguları, manyetik rezonans görüntüleme ve/veya kranial tomografi bulguları, etiyoloji, eşlik eden hastalıklar ve verilen antiepileptik tedaviler değerlendirildi.

Bulgular: Hastalarımızın yaş ortalaması 75 idi ve 50 (\%56) hasta erkekti. Doksan beş hastanın 55'inde (\%58) parsiyel tipte nöbet, 36'sında (\%38) jeneralize tonik klonik nöbet ve 4'ünde (\%4) jeneralize status epileptikus vardı. İnteriktal EEG'de fokal epileptiform aktivite sıklığ1 \%32,6 idi. Nöbetler hastaların \%85'inde (81 hasta) monoterapi ile \%15'inde (14 hasta) politerapiyle kontrol altında idi. Çalışmamız serebrovasküler hastalıkların, en sık (\%63) etyolojik neden olduğunu gösterdi. Yaş ve nöbet sıklığı ve EEG anormallikleri arasında anlamlı bir ilişki saptanmadı. Ancak yaş ve eşlik eden hastalıklar arasında anlamlı bir ilişki saptandı.

Sonuç: Sonuçlarımız fokal nöbetlerin yaşlı epilepsinin en sık belirtisi olduğunu desteklemektedir. Serebrovasküler hastalıklar yaşlılarda epilepsinin en fazla rastlanan etiyolojik nedenidir. Monoterapi hastaların çoğunluğunda yeterlidir. Yaşlı nüfusun devamlı büyümesi, doğru tanı ve etkili tedavi gereksinimini arttırmaktadır. (Türk Nöroloji Dergisi 2015; 21:62-7)

Anahtar Kelimeler: Epilepsi, nöbet tipi, EEG, tedavi, yaşlı hastalar

\section{Summary}

Objective: Epilepsy is frequently seen in the elderly, but its etiology, clinical presentation, comorbidities, and prognoses are different than younger patients. In this study, we investigated types of seizures, electroencephalography (EEG) findings and the cause of epilepsy in the elderly.

Materials and Methods: We retrospectively analyzed 95 patients who were 65 years old or older, and who had an epileptic seizure for the first time. Type of epilepsy, age, EEG findings, magnetic resonance imaging and/or cranial tomography findings, etiology, comorbidities and antiepileptic medication were evaluated.

Results: The average age of our patients was 75, and 50 (56\%) patients were male. Among 95 patients, 55 (58\%) had focal seizures, 36 (38\%) had generalized tonic-clonic seizures and $4(4 \%)$ had convulsive status epilepticus. The frequency of focal interictal epileptiform activity was $32.6 \%$ patients. Seizures were responsive to treatment administered as monotherapy in $81(85 \%)$ patients and as politherapy in $14(15 \%)$ patients. Our study showed that cerebrovascular disease was the most common (63\%) etiological cause identified. There was no significant relationship between age and frequency of seizures and EEG abnormalities. However, a significant correlation was found between age and comorbidities.

Conclusion: Our results supported the focal seizure is the most common manifestation of epilepsy in the elderly. Cerebrovascular disease is the most common etiological cause of epilepsy in the elderly. Monotherapy is sufficient in the majority of patients. Continuous growth of the elderly population is increasing the need for accurate diagnosis and effective treatment. (Turkish Journal of Neurology 2015; 21:62-7)

Key Words: Epilepsy, seizure type, EEG, treatment, elderly patients

Yazışma Adresi/Address for Correspondence: Dr. Belgin Petek Balcı, Haseki Eğitim ve Araştırma Hastanesi, Nöroloji Kliniği, İstanbul, Türkiye

Tel.: +90216462 2498 E-posta: belginp1@ yahoo.com

Geliş Tarihi/Received: 06.02.2015 Kabul Tarihi/Accepted: 05.03.2015 


\section{Giriş}

Epilepsinin tüm yaşlar için yaşam boyu prevalansı 10,3/1000'dir (1,5-57/1000) (1). Epidemiyolojik çalışmalarda nöbetlerin 75 ve üzeri yaşta daha sık görüldüğü bildirilmiştir (2,3). Epilepsi, kronik nörolojik hastalıklar arasında serebrovasküler hastalıklar (SVH) ve demanstan sonra 3. sıklıkta görülmektedir (4). Yaşlılarda akut gelişen bir hastalık durumunda provoke edilen nöbetlerin görülme sıklığı genç yaş grubuna oranla daha fazladır (5). Akut nöbetlerin \%30'u yaşlilarda status epileptikus olarak ortaya çıkmaktadır (5). Akut nöbetlerin ortaya çıkmasını metabolik ve elektrolit bozuklukları, hipo-hiper glisemi, üremi, hiponatremi, hipokalsemi, hipotiroidizm, enfeksiyonlar ve hepatik, kardiak ve solunum yetmezlikleri, akut dönem SVH'lar tetikleyebilmektedir $(5,6)$. Provoke edilmeyen nöbetlerde ise etiyolojiyi yaşlilarda öncelikle kronik dönemde SVH'lar, sessiz enfarktlar, demans, beyin tümörleri ve kafa travması oluşturmaktadır (2-5). Genç yaşta $\% 50$ oranında görülen fokal nöbet öncesi aura ve otomatizmalar yaşlılarda oldukça nadir görülür $(4,5,7)$. Bu nedenle yaşlilarda epilepsi prezentasyonu daha az spesifiktir. Ani bilinç kayıpları, konfüzyon epizodları, dikkatsizlik periodları, senkop atakları şeklinde görülüp geçici iskemik atak, geçici global amnezi, hipohiper glisemi, çeşitli kardiyak aritmiler ile karışabilmektedir (510).

Çalışmamızın amacı, epilepsi polikliniğine yönlendirilen 65 ve 65 yaş üstü hastalarda epilepsi nedenleri, nöbet tipleri ve EEG bulgularını klinik olarak analiz etmektir.

\section{Gereç ve Yöntem}

Çalışmamızda epilepsi polikliniğinde izlenen; ilk nöbeti 65 ve 65 yaş üzerinde başlayan, en az 2 kez aralıklı nöbet geçiren hastalar retrospektif olarak de ğerlendirildi. Metabolik bozukluk, enfeksiyon, organ yetmezlikleri gibi akut durumsal nöbet geçirenler çalışmaya dahil edilmedi. Hastalar 65-75 yaş aralığ 1 ve 75 yaş üstü olacak şekilde 2 yaş grubuna ayrıldı. Hastalarda rutin skalp elektroensefalografi (EEG) bulgular1, beyin tomografisi (BT) ve/veya beyin manyetik rezonans görüntüleme (MRG) bulguları ve eşlik eden diğer hastalıklar araştırıldı. Nöbet tipleri klinik öykü göz önüne alınarak sınıflandırıldı.

\section{Istatistiksel Analiz}

Tanımlayıcı istatistiklerle hastaların yaş, cinsiyet, nöbet sayıları, EEG bulguları, görüntüleme bulguları, nöbet çeşitleri ve ek hastalıkları belirlendi. Ardından EEG bulgusu olan ve olmayan, ek hastalığı olan ve olmayan hastalar olarak gruplara ayrıldı ve gruplar arasında yaş ve nöbet sayıları açısından Mann-Whitney U testi ile karşılaştırma yapıldı.

\section{Bulgular}

Takip süreleri 11 ay-10 yil (ortalama: 36,11 ay) arasında değişen 45'i kadın, 50'si erkek 95 hasta değerlendirildi. Altmış beş-75 yaş aralığında 42 hasta, 75 yaş ve üstü aralığında 53 hasta vardı. Ortalama yaş 76,53 (ss: 5,78 dağılım aralığ 1 65-91) olup, cinsiyetler arası belirgin fark saptanmadı. Ortalama nöbet sayısı 3,42 (ss:1.60, dağılım aralığ: $1-7$ ) idi ve cinsiyetler arası belirgin fark yoktu.

Hastalarımızda en fazla görülen nöbet tipi $(\% 57,8)$ parsiyel nöbetlerdi ve en çok basit parsiyel nöbet (BPN) görülmekteydi (Tablo 1). EEG bulguları incelendiğinde en sik $(\% 32,6)$ fokal yavaşlama ve fokal epileptik deşarjlar görüldü. Yirmi iki hastanın EEG'si normaldi, jeneralize tonik klonik nöbet (JTKN) geçiren 36 hastadan 34'ünün EEG'de ise jeneralize epileptiform deşarj saptanmadı. Yaş grupları arasında EEG bulguları karşılaştırıldı $\breve{g}_{1}$ nda belirgin fark olmadı $\breve{g}_{1}$ saptand 1 (Tablo 2).

Üç hasta dişında tüm hastalara kranial görüntüleme (BT/ MRG) yapıldı. Hastalarda en çok SVH, daha sonra lökoareozis ve kortikal atrofi saptand. Laküner enfarkt ve hematom 65-75 yaş aralığında fazla iken geniş damar enfarktı 75 yaş ve üzerinde fazlaydı (Tablo 3). Serebrovasküler hastalık ile nöbet gelişiminin zamansal bağlantısı 34 hastada netleştirilebildi. On iki $(\% 35,3)$ hastada inme sonrası erken nöbet, $22(\% 64,7)$ hastada ise geç nöbet geliştiği öğrenildi.

Hastaların 30'unda eşlik eden başka bir hastalık yoktu; 65 hastada epilepsinin yanında ek bir ya da birden fazla hastalığın olduğu tespit edildi (Tablo 4). Hastalarımız EEG bulgusu varlığ ve ek hastalık varlığına göre nöbet sayısı ve yaş grupları açısından analiz edildiğinde, yaşa bağlı olarak ek bir hastalığın görülme sıklı̆̆ 1 istatistiksel olarak anlamlı derecede artmıştı $(\mathrm{p}=0,013)$ (Tablo 5). Nöbet sıklığı ile ek hastalık arasında bir bağlantı saptanamadi.

Hastalarımızın \%85'inin nöbetleri monoterapi ile kontrol altındaydı (Tablo 6). Politerapi alanların yalnızca 1'i üçlü tedavi alırken diğgerleri ikili tedavi almaktaydı. Remisyonda olan hasta bulunmayıp, dirençli epileptik nöbeti olan hastamız yoktu.

\section{Tartışma}

Epilepsi çocuk, ergen ve genç erişkin hastalı̆̆ 1 gibi düşünülse de yaşlılarda da yüksek oranda görülmektedir. İleri yaşta epilepsi,

Tablo 1. Hastaların nöbet tipleri*

\begin{tabular}{lllllll}
\hline Nöbet Tipleri & Hasta Sayısı (n) & $\mathbf{n}(\%)$ & $\mathbf{6 5 - 7 5}$ y & $\mathbf{6 5 - 7 5}$ y (\%) & $\geq 75$ y & $\geq 75$ y $(\%)$ \\
\hline JTKN & 36 & 37,9 & 13 & 30,9 & 23 & 73,4 \\
BPN & 19 & 20 & 12 & 28,6 & 13,2 \\
BPN ve SJN & 16 & 16,8 & 7 & 16,7 & 9 & 16,9 \\
KPN & 12 & 12,6 & 7 & 16,7 & 5 & 9,4 \\
KPN ve SJN & 8 & 8,4 & 3 & 7,1 & 5 & 9,4 \\
KSE & 4 & 4,2 & 0 & 0 & 4,5 \\
\hline
\end{tabular}

JTKN: Jeneralize tonik klonik nöbet, SJN: Sekonder jeneralize nöbet, BPN: Basit parsiyel nöbet, KPN: Kompleks parsiyel nöbet, KSE: Konvulzif status epileptikus *Hasta ve hasta yakınlarından alınan öyküye dayanılarak sınıflandırılmıştır. 
inme ve demanstan sonra üçüncü sıklıkta görülmektedir (3). Günümüzde beklenen yaşam süresinin artmasıyla yaşlı epilepsi insidansını da arttırmaktadır $(6,7,11)$. Epilepsi insidansı toplumda 100,000 'de 80,8 iken; 65-69 yaş arası 100,000'de 85, 80 yaş sonrası ise 100,000'de 135'tir (12).

Yaşlı hastalarda çoğunlukla parsiyel nöbetler görülmektedir. Biz de çalışmamızda en sık $(\% 57,8)$ parsiyel nöbet, ikinci sıklıkta $(\% 37,9)$ JTNK saptadık. Ancak alt grupları incelediğimizde 75 ve üzeri yaşta JTNK sıklı̆̆ının arttı̆̆ $1 \% 43,4)$ ve parsiyel nöbetlere yakın oranlarda olduğunu $(\% 48,3)$ tespit ettik. Parsiyel nöbet geçiren hastalarınızın çoğunluğunu $(\% 36,8)$ basit parsiyel nöbetler (BPN) oluşturuyordu. Daha önceki çalışmalardan farklı olarak hastalarımızda JTNK oranı yüksek $(\% 37,9)$ bulundu $(4,5,9)$. Ancak JTNK geçiren hastaların EEG incelemelerinde jeneralize epileptiform deşarj oranlarının düşük bulunması, hatta çoğunlukla fokal bulguların görülmesi nedeniyle JTNK geçirdiği ifade edilen hastaların bir kısmında nöbet anamnezinin çok iyi alınmamış olabileceği düşünüldü. Mısırlı ve ark.'nın çalışmalarında da bizim çalışmamıza benzer şekilde jeneralize nöbet oranı yüksek (\%46) bildirilmiştir (13). Paradowski ve ark.'nın çalışmasında JTNK geçirenler \%33,8 kompleks parsiyel nöbet (KPN) geçirenler \%65,2 olarak bildirilmiştir (4). Aynı çalışmada hasta alt grupları arasında yaş oranı yükseldikçe KPN sıklığının arttığ 1 tespit edilmiştir. Bizim hastalarımızda ise her iki yaş grubunda da parsiyel nöbetlerin fazla olduğu gözlenmekle birlikte, 75 yaş ve üzeri grupta JTNK nöbetlerin arttı̆̆ ${ }_{1}$ dikkati çekiyordu.

Hastalarımızın \%67,4’ünün EEG'leri anormaldi, çoğu fokal olmak üzere \%35,8’i epileptiform aktivite göstermekteydi. Yaş grupları arasında EEG bulgularında fark yoktu. Sinha ve ark., çalışmamıza benzer şekilde inceledikleri hastaların 2/3'ünde EEG bozukluğu ve bu hastaların da yaklaşık yarısında epileptiform aktivite saptamışlardır (9). Tanaka ve ark. da çalışmalarında hastaların EEG'lerinde \%72,9 $(\mathrm{n}=51)$ fokal epileptiform deşarj, $\% 11,4(\mathrm{n}=8)$ fokal ya da jeneralize yavaşlama, \%15,7 $(\mathrm{n}=11)$ normal olarak bildirmişlerdir (14). Yaşlı epileptiklerde hasta ve hasta yakınlarından alınan klinik öyküye dayanarak gruplama yapıldı̆̆ında JTNK sıklığı yüksek iken, bu oran rutin skalp EEG'sine yansımamaktadır. Önceki çalışmalarda bildirildiği gibi yaşlılarda rutin skalp EEG'sinin tanı sensitivitesi ve

Tablo 2. Hastaların elektroensefalografi bulguları

\begin{tabular}{|c|c|c|c|c|c|c|}
\hline EEG bulguları & Hasta sayısı (n) & $\mathrm{n}(\%)$ & $65-75 y$ & $65-75$ y $(\%)$ & $\geq 75 y$ & $\geq 75$ y $(\%)$ \\
\hline EEG yapılamayan & 9 & 9,5 & 7 & 16,7 & 2 & 3,8 \\
\hline Normal EEG & 22 & 21,05 & 10 & 23,8 & 12 & 22,6 \\
\hline DY & 6 & 6,3 & 2 & 4,8 & 4 & 7,5 \\
\hline FY ve FED & 31 & 32,6 & 14 & 33,3 & 17 & 32,1 \\
\hline JED & 2 & 2,1 & 1 & 2,4 & 1 & 1,9 \\
\hline
\end{tabular}

FY: Fokal yavaşlama, DY: Diffüz yavaşlama, FED: Fokal epileptik deşarj, SJFED: Sekonder jeneralize fokal epileptik deşarj, JED: Jeneralize epileptik deşarj, EEG: Elektroensefalografi

Tablo 3. Hastaların görüntüleme bulguları

\begin{tabular}{|c|c|c|c|c|c|c|}
\hline Görüntüleme (BT/MRG) & Hasta sayısı n & n $(\%)$ & $65-75 y$ & $65-75$ y $(\%)$ & $\geq 75 y$ & $\geq 75$ y $(\%)$ \\
\hline Görüntüleme yapılamayan & 3 & 3,2 & 1 & 2,4 & 2 & 3,8 \\
\hline Normal & 7 & 7,4 & 5 & 11,9 & 2 & 3,8 \\
\hline Geniş damar enfarktı & 39 & 41,1 & 17 & 40,5 & 22 & 41,5 \\
\hline Laküner enfarkt & 13 & 13,7 & 7 & 16,7 & 6 & 11,3 \\
\hline Hematom (kronik dönem) & 7 & 7,4 & 5 & 11,9 & 2 & 3,8 \\
\hline Hematom ve enfarkt & 1 & 1,1 & 1 & 2,4 & 0 & 0 \\
\hline Kortikal atrofi & 6 & 6,3 & 0 & 0 & 6 & 11,3 \\
\hline Lökoareozis & 8 & 8,4 & 1 & 2,4 & 7 & 13,2 \\
\hline Ensefalomalazi & 3 & 3,2 & 3 & 7,2 & 0 & 0 \\
\hline Anjiom & 2 & 2,1 & 1 & 2,4 & 1 & 1,9 \\
\hline Sinüs trombozu & 2 & 2,1 & 1 & 2,4 & 1 & 1,9 \\
\hline Subdural hematom & 1 & 1,1 & 0 & 0 & 1 & 1,9 \\
\hline Yer kaplayan lezyon (meningiom) & 1 & 1,1 & 0 & 0 & 1 & 1,9 \\
\hline Küçük damar hastalığ1 ve Kortikal atrofi & 2 & 2,1 & 0 & 0 & 2 & 3,8 \\
\hline
\end{tabular}

BT: Beyin tomografisi, MRG: Manyetik rezonans görüntüleme 
spesifitesi düşüktür (6). Bu nedenle klinik öykü ve rutin skalp EEG bulguları tanı için yeterli olmadığında uzun süreli video EEG monitorizasyonunun tanı koymada yardımcı olabileceği bildirilmiştir $(4,6)$. Hastalarımızda klinik olarak tanı şüphesi olmamakla birlikte epilepsi sınıflandırılması açısından EEG ve nöbet tipi uyumu olmayan hastalarda uzun süreli video EEG monitorizasyonun yararlı olabileceği düşünüldü. Karaçayır ve ark. inme sonrası nöbet geçiren hastaların EEG'de çalışmamıza benzer şekilde en çok fokal yavaşlama ve fokal epileptik deşarj saptadıklarını bildirmişlerdir $(15,16)$.

Yaşlı epileptiklerin etiyolojisinde ilk sırada SVH daha sonra nörodejeneratif hastalıklar, beyin tümörü, travma ve diğer nedenler gelmektedir $(7,13)$. Toplum bazlı epidemiyolojik çalışmaların sonuçları SVH sonrası ilk yılda epilepsi riskinin toplum geneline göre 17 kat arttı̆̆ını göstermektedir (17). Biz de kranial görüntülemelerde en çok SVH $(\% 63,2)$ tespit ettik. Serebrovasküler hastalıkları olan hastalarımızda en fazla
$39(\% 41,1)$ geniş damar enfarktı, sonra sırasıyla $13(\% 13,7)$ laküner enfarkt ve $7(\% 7,4)$ kronik dönem hematom saptadık. Bulgularımız önceki çalışmaların sonuçlarına benzerdi (1416,18). İnme sonrası kortikal etkilenme epileptik nöbetlerde belirli risk faktörü olmakla birlikte yapılan çalışmalarda sadece subkortikal tutulumun da nöbetlere yol açabildiği bildirilmiştir (16). Paradowski ve ark. yaptıkları çalışmada en sık neden olarak SVH saptadıklarını, bir hastada sessiz enfarkt tespit ettiklerini, en yaşlı alt grupta ise SVH dışında lökoareozis saptadıklarını bildirmişlerdir (4). Aynı çalışmada yaş oranı arttıkça lökoareozisin daha fazla görüldüğünü $(\% 56,5)$ bunun kan akımının azalmasına bağlı farklı serebral korteks alanlarında oksijen tüketiminin azalması ile epileptik risk faktörü olabileceğini bildirmişlerdir (4). Bizim hasta alt grupları içinde lökoareozis ve kortikal atrofi 75 yaş ve üzerinde istatiksel olarak anlamlılık ifade etmese bile daha fazla gözlenmiştir. Çalışmamızda etiyolojik neden olarak kafa travması saptanmazken, beyin tümörü \%1,1 bulunmuştur. Bir çok

Tablo 4. Hastaların epilepsi dışı ek hastalıkları

\begin{tabular}{|c|c|c|c|c|}
\hline Ek hastalık & Hasta sayısı (n) & $\mathrm{n}(\%)$ & $65-75 y$ & $\geq 75 \mathrm{y}$ \\
\hline Hastalığ1 yok & 30 & 31,6 & 19 & 11 \\
\hline HT & 21 & 22,1 & 9 & 12 \\
\hline DM & 6 & 6,3 & 4 & 2 \\
\hline HL & 5 & 5,3 & 0 & 5 \\
\hline Demans & 9 & 9,5 & 2 & 7 \\
\hline Depresyon & 2 & 2,1 & 0 & 2 \\
\hline $\mathrm{PH}$ & 2 & 2,1 & 0 & 2 \\
\hline $\mathrm{DM}+\mathrm{HT}$ & 5 & 5,3 & 1 & 4 \\
\hline $\mathrm{HT}+\mathrm{KY}$ & 5 & 5,3 & 3 & 2 \\
\hline KY+by-pass operasyonu & 2 & 2,1 & 1 & 1 \\
\hline Tiroid Bozuklukları & 1 & 1,1 & 0 & 1 \\
\hline $\mathrm{DM}+$ Depresyon+PH & 2 & 2,1 & 2 & 0 \\
\hline Astım & 1 & 1,1 & 1 & 0 \\
\hline MM & 1 & 1,1 & 0 & 1 \\
\hline İKH & 1 & 1,1 & 0 & 1 \\
\hline $\mathrm{PH}+\mathrm{HT}+$ Demans & 1 & 1,1 & 0 & 1 \\
\hline $\mathrm{HT}+\mathrm{PH}$ & 1 & 1,1 & 0 & 1 \\
\hline
\end{tabular}

HT: Hipertansiyon DM: Diabetes mellitüs, KY: Kalp yetmezliği, HL: Hiperlipidemi, PH: Parkinson hastalı̆ı̆, MM: Multipl myelom, İKH: İskemik kalp hastalığı

Tablo 5. Elektroensefalografi bulgusu ve ek hastalık varlığına göre yaş ve nöbet sayılarının karşılaştırılması

\begin{tabular}{|c|c|c|c|c|}
\hline & \multicolumn{2}{|c|}{ EEG bulgusu } & \multirow{2}{*}{$\mathbf{z}$} & \multirow{2}{*}{$\mathrm{p}$} \\
\hline & $\operatorname{Var}(n=64)$ & Yok $(n=22)$ & & \\
\hline Yaş & $77,38 \pm 6,09$ & $74,82 \pm 4,82$ & $-1,62$ & 0,106 \\
\hline \multirow{2}{*}{ Nöbet Sayısı } & Ek Hastalık & & & \\
\hline & $\operatorname{Var}(\mathrm{n}=65)$ & Yok $(n=30)$ & & \\
\hline Nöbet Sayısı & $3,47 \pm 1,48$ & $3,40 \pm 1,66$ & $-0,53$ & 0,596 \\
\hline
\end{tabular}

EEG: Elektroensefalografi 
Tablo 6. Hastaların kullandığı antiepileptik ilaçlar

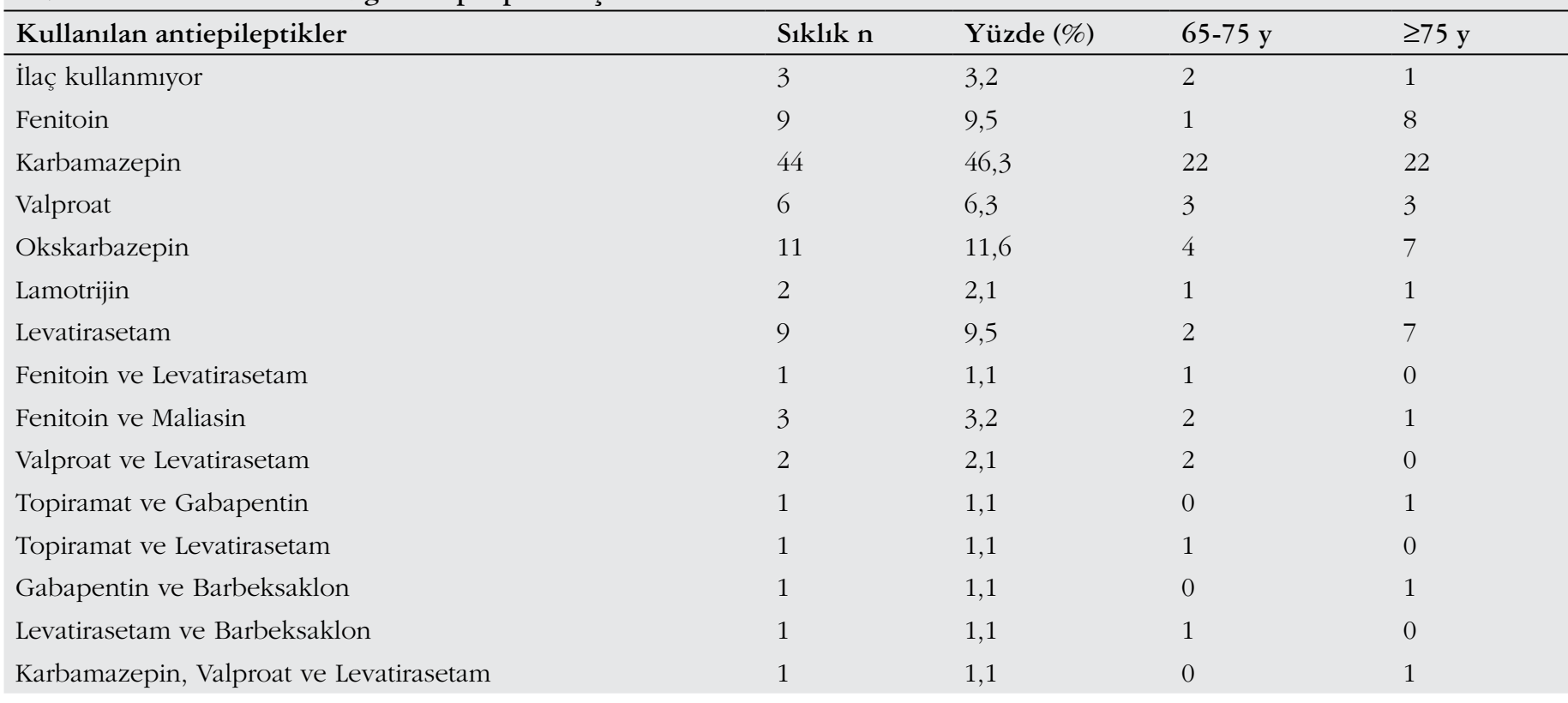

çalışma etiyolojik neden olan kafa travmalarını (kronik alkolizme bağl1) \%3-4 ve beyin tümörünü \%5-10 olarak bildirmiştir (15). Çalışmamızda bu oranın çok düşük olması hastanemizde kafa travması ve beyin tümörüne bağlı epileptik nöbetlerin nöroşirurji kliniği tarafından takip edilmesine bağlı olabilir.

Hastalarımızın tamamına yakınında (\%96,8) kranial görüntüleme (BT/MRG) yapıldı. Hastalarımızın \%63,2'sinde vasküler lezyon, \%8,4'ünde lökoareosiz ve \%6,3'ünde kortikal atrofi saptandı. Laküner enfarkt ve hematom $65-75$ yaş aralığında fazla iken geniş damar enfarktı 75 yaş ve üzerinde fazlaydı. Çalışmamızda SVH ile nöbet gelişiminin zamansal bağlantısı 34 hastada netleştirilebildi. $12(\% 35,3)$ hastada inme sonrası erken nöbet, $22(\% 64,7)$ hastada ise geç nöbet geliştiği öğrenildi. Temprano ve ark.'nın çalışmasında SVH sonrası nöbetler bizimki ile benzer olarak erken dönemde \%36,6, geç dönemde \%63,4 olarak bildirilmiştir (10). İnme sonrası geç başlangıçlı nöbetlerde kortikal ve geniş enfarktların riski anlamlı derecede arttırdığı bir çok çalışmada bildirilmiştir $(19,20)$.

Hastalarımızda epilepsi dışında ek hastalık olarak en fazla hipertansiyon $(\% 22,1)$, daha sonra demans $\% 9,5$ görüldü. Demansta epilepsi insidansı çok değişken oranlarda (\%5-64) bildirilmiştir (21). Non-vasküler demans ve Alzheimer hastalığı ilerlediğinde epileptik nöbet geçirme insidansı artmaktadır. Ayrıca erken başlayan demanslarda da nöbet geçirme riskinin yüksek olduğu bildirilmiştir $(21,22)$. Bizim hastalarımızın büyük çoğunluğu 75 ve üzeri yaş grubundaydı ve hiçbiri erken evre demans değildi. Hastalarımızda ayrıca HT, Hiperlipidemi 75 ve üzeri yaş grubunda daha fazla iken DM 65-75 yaş aralı̆̆ında fazla idi.

Yaşlı epileptik hastalarda epilepsi nöbetleri genellikle iyi huyludur ve tekli antiepileptiklere iyi yanıt vermektedir. Tanaka ve ark. çalışmalarında monoterapi ile nöbetleri kontrol altında olan yaşlı hastaların oranı \% 77,8 olarak bildirilmiştir (23). Bizim çalışmamızda da hastaların \%85'inin nöbetleri monoterapi ile kontrol altındaydı. Hastalarımızın büyük çoğunluğu $(\% 46,3)$ karbamazepin ve okskarbazepin $(\% 11,6)$ kullanmaktayd.
Hastalarımızda EEG bulgusu varlığ 1 ile yaş ve nöbet sıklığ 1 arasında bir bağıntı yoktu. Ek hastalık varlığ 1 ve nöbet sıklığ 1 arasında da bir bağıntı saptanmadı ancak ek hastalık varlı̆̆ı ve yaş arasında istatistiksel olarak anlamlılık saptandı $(\mathrm{p}=0,013)$. Literatür incelendiğinde daha önce bu konuyu irdeleyen bir araştırmaya rastlanmadı.

Hastalarımızın \%37'sinde etiyolojik neden tam olarak saptanamadı. Etiyolojik neden bulunamayanların \%21'inde kortikal atrofi, periventriküler iskemi ve lökoareozis, küçük damar hastalığı gibi yaş oranı yükseldikçe görülme sıklığı artan, fakat epilepsi patojenezinde yeri tartışmalı lezyonlar mevcuttu. Önceki çalışmalarda da bizim bulgularımızı destekler şekilde yaşlı epileptiklerin çoğunluğunda etiyolojik neden olarak en fazla SVH saptanmıştır $(5-7,13)$.

Sonuç olarak yaşlılıkta ortaya çıkan epilepsilerin çoğunluğu parsiyel nöbetler şeklinde olup monoterapi ile kontrol altına alınabilmektedir. Ancak yaşlılarda parsiyel nöbetlerin bazen sadece konfüzyonel atak şeklinde ortaya çıkması ve klinik öyküde belirtilen nöbet tipinin rutin skalp EEG'sine yansımayabilmesi nedeniyle bazen eksik veya yanlış tanı konulabilmektedir. Bu yüzden yaşlı epileptik hastalarda rutin EEG'nin yanı sıra videoEEG incelemesinin yapılması tanı koymada yararlı olabilir. Yaş artımı ile birlikte epilepsi yanında ek hastalık bulunma oranı artmaktadır. Ancak, sevindirici bir şekilde ek hastalık ile nöbet sıklı̆̆ı arasında bağlantı bulunmamıştır. Yaşlılarda epilepside etiyolojik neden olarak en çok SVH görülmekle birlikte nörodejeneratif süreçler açısından düzenli aralarla yapılacak klinik ve görüntüleme takipleri nedeni ortaya koymada yararlı olacaktır.

\section{Teşekkür}

Çalışmanın istatistik hesapları için verdiğ $i$ destekten dolayı İlhan Atagün'e teşekkür ederiz.

Etik Kurul Onayı: Çalışmanın etik kurul onayı alınmıştır.

Hasta Onayı: Çalışma retrospektif tarama çalışması olduğundan hasta onamı alınmamıştır.

Konsept: Belgin Petek Balcı, Aytül Mutlu, Feriha Özer 
Dizayn: Belgin Petek Balcı, Aytül Mutlu

Veri Toplama veya İşleme: Belgin Petek Balc1, Aytül Mutlu, Özlem Çokar

Analiz veya Yorumlama: Belgin Petek Balcı, Aytül Mutlu, Özlem Çokar Özer

Literatür Arama: Belgin Petek Balc1, Aytül Mutlu, Feriha

Yazan: Belgin Petek Balc1

Hakem Değerlendirmesi: Editörler kurulu ve Editörler kurulu dışında olan kişiler tarafından değerlendirilmiştir.

Çıkar Çatışması: Yazarlar tarafından çıkar çatışması bildirilmemiştir.

Finansal Destek: Yazarlar tarafından finansal destek almadıklarını bildirmişlerdir.

\section{Kaynaklar}

1. Sander JW, Shorvon SD. Epidemiology of the epilepsies. J Neurol Neurosurg Psychiatry 1996;61:433-443.

2. Miskov S, Roje Bedekovic M, Mikula I, Demarin V. Etiology and treatment of epilepsy in the elderly. Acta Med Croatica 2005;59:63-67.

3. Cloyd J, Hauser W, Towne A, Ramsey R, Mattson R, Gilliam F, Walczak T. Epidemiological and medical aspects of epilepsy in the elderly. Epilepsy Res 2006;68(Suppl 1)39-48.

4. Paradowski B, Zagrajek MM. Epilepsy in middle-aged and elderly people: a three-year observation. Epileptic Disord 2005;7:91-95.

5. Brodie MJ, Kwan P. Epilepsy in elderly people. BMJ 2005;331:1317-1322.

6. Brodie MJ, Elder AT, Kwan P, Epilepsy in later life. Lancet Neurol 2009;8:10191030.

7. Werhahn KJ. Epilepsy in the elderly. Nervenarzt 2012;83:201-204.

8. Arain AM, Abou-Khalil BW. Management of new-onset epilepsy in the elderly. Nat Rev Neurol 2009;5:363-371.
9. Sinha S, Satishchandra P, Kalband BR, Thennarasu K. EEG observations in elderly with new onset seizures: from developing country perspective. J Clin Neurophysiol 2011;28:388-393.

10. Temprano T, Salas-Puig J, Calleja-Puerta S, Zanabili Al-Sibbai AA, Lahoz CH. Post-stroke epilepsy. Rev Neurol 2009;48:171-177.

11. Hauser WA. Seizure disorders:the changes with age. Epilepsia 1992;33(suppl 4):6-14.

12. Wallace H, Shorvon S, Tallis R. Age-specific incidence and prevalence rates of treated epilepsy in an unselected population of 2,052,922 and age- specific fertility rates of women with epilepsy. Lancet 1998;352:1970-1973.

13. Mısırlı CH, Erdoğan N, Tunalı F, Aktura D, Tanyel T. Yaşlı hastalarda epilepsi profili. Epilepsi 2014;20:35-38.

14. Tanaka A, Akamatsu N, Shouzaki T, Toyota T, Yamano M, Nakagawa M, Tsuji S. Clinical characteristics and treatment responses in new-onset epilepsy in the elderly. Seizure 2013;22:772-775.

15. Karaçayır SS, Balcı K, Asil T, Çelik Y. Beyin damar hastalığı sonrası gelişen epileptik nöbetler. Balkan Med J 2006;23:127-134.

16. Misirli H, Ozge A, Somay G, Erdoğan N, Erkal H, Erenoğlu NY. Seizure development after stroke. Int J Clin Pract 2006;60:1536-1541.

17. Jungehulsing GJ, Heuschmann PU, Holfkamp M, Schwab S, KolominskyRabas PL. Incidence and predictors of post-stroke epilepsy. Acta Neurol Scand 2013;127:427-430.

18. So EL, Annegers JF, Hauser WA, O'Brien PC, Whisnant JP. Population-based study of seizure disorders after cerebral infarction. Neurology 1996;46:350-355.

19. Velioğlu SK, Ozmenoğlu M, Boz C, Alioğlu Z. Status epilepticus after stroke. Stroke 2001;32:1169-1172.

20. Okuda S, Takano S, Ueno M, Hamaguchi H, Kanda F. Clinical features of lateonset poststroke seizures. J Stroke Cerebrovasc Dis 2012;21:583-586.

21. Conrad J, Pawlowski M, Dogan M, Kovac S, Ritter MA, Evers S. Seizures after cerebrovascular events: risk factors and clinical features. Seizure 2013;22:275-282.

22. Friedman D, Honig LS, Scarmeas N. Seizures and epilepsy in Alzheimer's disease. CNS Neurosci Ther 2012;18:285-294.

23. Scarmeas N, Honig LS, Choi H, Cantero J, Brandt J, Blacker D, Albert M, Amatniek JC, Marder K, Bell K, Hauser WA, Stern Y. Seizures in Alzheimer Disease: who, when, and how common? Arch Neurol 2009;66:992-997. 